\title{
Hsp90 inhibitor 17-AAG inhibits stem cell-like properties and chemoresistance in osteosarcoma cells via the Hedgehog signaling pathway
}

\author{
XIONG SHU ${ }^{1}$, HUIQI LIU ${ }^{2}$, RUI ZHEN ${ }^{1}$, YONGSHENG JIE ${ }^{1}$, LEI CHEN ${ }^{1}$, HUI QI $^{1}$, \\ CHAO WANG $^{1}$, RENXIAN WANG ${ }^{1}$, DAFU CHEN $^{1}$ and YULIANG RAN ${ }^{3}$
}

\begin{abstract}
${ }^{1}$ Laboratory of Bone Tissue Engineering, Beijing Laboratory of Biomedical Materials, Beijing Research Institute of Orthopaedics and Traumatology, Beijing JiShuiTan Hospital, Beijing $100035 ;{ }^{2}$ Department of Basic Medical Science, Medical School of Qinghai University, Xining, Qinghai 810016; ${ }^{3}$ State Key Laboratory of Molecular Oncology, National Cancer Center/National Clinical Research Center for Cancer/Cancer Hospital, Chinese Academy of Medical Sciences and Peking Union Medical College, Beijing 100021, P.R. China
\end{abstract}

Received December 13, 2019; Accepted April 8, 2020

DOI: $10.3892 /$ or.2020.7597

\begin{abstract}
Multiple drug resistance is a major obstacle to the successful treatment of osteosarcoma (OS). Recent studies have demonstrated that a subset of cells, referred to as OS stem cells (OSCs), play a crucial role in the acquisition of multiple drug resistance. Therefore, an improved understanding of OS biology and pathogenesis is required to advance the development of targeted therapies aimed at eradicating this particular subset of cells in order to reverse acquired chemoresistance in OS. The aim of the present study was to assess the anti-OSC effects of 17-AAG and determine the underlying molecular mechanism. Heat shock protein 90 expression was found to be increased in sarcosphere cells and was positively associated with cancer stem cell characteristics. In addition, 17-AAG was able to suppress the stem cell-like phenotype of OS cells. Mechanistically, 17-AAG inhibited OSC-like properties and chemoresistance through glycogen synthase kinase (GSK) $3 \beta$ inactivation-mediated repression of the Hedgehog signaling pathway. The findings of the present study provided comprehensive evidence for the inhibition of OSC properties
\end{abstract}

Correspondence to: Dr Yuliang Ran, State Key Laboratory of Molecular Oncology, National Cancer Center/National Clinical Research Center for Cancer/Cancer Hospital, Chinese Academy of Medical Sciences and Peking Union Medical College, 17 Panjiayuan Nanli, Chaoyang, Beijing 100021, P.R. China

E-mail: ran_yuliang@126.com

Dr Dafu Chen, Laboratory of Bone Tissue Engineering, Beijing Laboratory of Biomedical Materials, Beijing Research Institute of Orthopaedics and Traumatology, Beijing JiShuiTan Hospital, 31 Xinjiekou E Road, Xicheng, Beijing 100035, P.R. China

E-mail: chendafu@jsthospital.org

Key words: osteosarcoma, cancer stem cell, 17-AAG, chemoresistance, Hedgehog signaling pathway and chemoresistance by $17-\mathrm{AAG}$ through repression of the GSK3 $3 /$ Hedgehog signaling pathway, suggesting that $17-A A G$ may be a promising therapeutic agent for targeting OSCs.

\section{Introduction}

Osteosarcoma (OS) is the most common type of primary malignant bone tumor and it primarily affects children and adolescents (1). The outcome of patients with OS may improve through a combination of surgery and chemotherapy, and the 5 -year survival rate has increased to $60-70 \%$ over the past 30 years $(2,3)$. However, a considerable number of patients are either not sensitive to chemotherapy or develop drug resistance to the currently available chemotherapeutic regimens (4). Therefore, it is crucial to elucidate the mechanisms underlying the development of chemoresistance in these patients and to develop new strategies for the treatment of OS.

Numerous studies have demonstrated that cancer stem cells (CSCs) are not only the cause of relapse and metastasis, but also contribute to chemoresistance in tumors (5-8). OS stem cells (OSCs) have recently been identified as a subset of CSCs using a distinct set of stem cell markers, including CD133, aldehyde dehydrogenase 1 (ALDH1), CD117/Stro-1 and CD271 (9-12). Additional stem cell markers, such as octamer-binding transcription factor 4 (Oct-4), sex determining region Y-box 2 (Sox 2) and Nanog, have also been recommended for distinguishing OSC populations from other cells (13-15). OS sarcosphere cells exhibit CSC characteristics and display high expression levels of markers associated with stem cell self-renewal, tumorigenicity, and multiple drug resistance (16).

The heat shock protein (Hsp)90 inhibitor, 17-AAG (tanespimycin), interferes with the binding of ATP to Hsp90 and results in the proteasome-mediated degradation of Hsp90 client protein complexes $(17,18)$. 17-AAG significantly enhances the cytotoxicity of etoposide in human colon cancer HCT116 cells (19). As known Hsp90 client proteins are required for the maintenance of self-renewal, this requirement for self-renewal 
may be exploited by treatment with 17-AAG. Indeed, several studies have demonstrated that 17-AAG can effectively target CSCs $(20,21)$. However, little is known on the effects of 17-AAG on OSCs, and the molecular mechanisms underlying its antitumor activity remain to be determined.

The Hedgehog signaling pathway plays a key role in the development of several CSCs, such as glioblastoma stem cells, CD34+ leukemic cells and gastric CSCs (22-24). The Hedgehog signaling pathway is primarily dependent on the Gli transcription factor family (Gli1-3), which are its downstream effectors. Specifically, Gli1 is the principal transcriptional effector that regulates gene expression in response to Hedgehog signaling activation (25). However, its clinical significance and biological function in OS chemoresistance remains unclear. In the present study, the human OS cell lines MG-63 and Saos-2 were examined for their expression of the putative stem cell markers CD133, ALDH1, CD117/Stro-1 and CD271. The efficacy of 17-AAG in inhibiting stem cell-like properties and chemoresistance in OS cells was then investigated. The aim of the present study was to explore how 17-AAG interacts with OSCs and to determine the mechanism underlying 17-AAG-mediated suppression of stemness. Furthermore, it was investigated whether one of the mechanisms underlying the action of 17-AAG was the induction of glycogen synthase kinase (GSK) $3 \beta$ inactivation-mediated repression of the Hedgehog pathway, which is crucial for the development of OS. The findings of the present study may provide insight into acquired drug resistance and indicate novel treatment strategies to prevent or overcome this resistance, which may improve the prognosis and survival of patients with OS.

\section{Materials and methods}

Cell culture and reagents. The MG-63 and Saos-2 human OS cell lines were purchased from the China Center for Type Culture Collection. MG-63 cells were maintained in RPMI-1640 medium (Gibco; Thermo Fisher Scientific, Inc.) supplemented with $10 \%$ FBS (Gibco; Thermo Fisher Scientific, Inc), $1 \%$ L-glutamine and $1 \%$ penicillin-streptomycin sulfate (Thermo Fisher Scientific, Inc.). Saos-2 cells were cultured in McCoy's 5A medium (Gibco; Thermo Fisher Scientific, Inc.), supplemented with $10 \%$ FBS, $1 \%$ L-glutamine and $1 \%$ penicillin-streptomycin sulfate. 17-AAG was purchased from Selleck Chemicals. Methotrexate and cisplatin were purchased from Pfizer, Inc.

Serum-free medium (SFM) was comprised of DMEM/F12, supplemented with $20 \mu \mathrm{l} / \mathrm{ml} \mathrm{B} 27$ and $20 \mathrm{ng} / \mathrm{ml}$ basic fibroblast growth factor (bFGF) (all from Gibco; Thermo Fisher Scientific, Inc.). OSCs were isolated from two cell lines using SFM and were assessed for their ability to form sphere-like cell aggregates in $<7$ days. These cells were collected and disassociated with $2.5 \%$ trypsin, and viable cells were counted using trypan blue (Sigma-Aldrich; Merck KGaA) exclusion. All cultures were maintained in a $37^{\circ} \mathrm{C}$ incubator with $5 \%$ $\mathrm{CO}_{2}$.

Sphere formation assay. MG-63 and Saos-2 cells were plated in each well (500 cells/well) of Ultra-Low Attachment 24-well plates (Corning, Inc.) with $0.8 \%$ methyl cellulose (Sigma-Aldrich; Merck KGaA) supplemented with $20 \mu \mathrm{l} / \mathrm{ml}$
B27, $20 \mathrm{ng} / \mathrm{ml} \mathrm{bFGF}, 10 \mathrm{ng} / \mathrm{ml}$ epidermal growth factor, 1\% L-glutamine and $1 \%$ penicillin-streptomycin sulfate (all from Thermo Fisher Scientific, Inc.). Every 3 days, each well was examined under a light microscope (IX71; Olympus Corporation).

Flow cytometry and fluorescence-activated cell sorting (FACS). Cells were detached into single-cell suspensions using trypsin-EDTA, followed by staining of $1 \times 10^{6}$ cells in $500 \mu \mathrm{l}$ PBS/0.5\% BSA (Sigma-Aldrich; Merck KGaA) with fluorescence-labeled primary antibodies (1-5 $\mu \mathrm{l})$, including CD133-PE (1:10; cat. no. 130-112-195; Miltenyi Biotec GmbH), Aldeflour $^{\mathrm{TM}}$ kit (cat. no. 01700; Stemcell Technologies, Inc.) and CD271-fluorescein isothiocyanate (1:400; cat. no. 746728; BD Biosciences) at $4^{\circ} \mathrm{C}$ for $60 \mathrm{~min}$. After washing, labeled cells were analyzed and sorted immediately using a BD FACS AriaIII system (BD Biosciences). A blank control without labeling was used to delineate any unstained populations and analyzed by FlowJo 7.6.1. (FlowJo LLC).

Reverse transcription-quantitative polymerase chain reaction (RT-qPCR) analysis. Total RNA was prepared and detected as previously described (26). First-strand cDNA was synthesized using a RevertAid First Strand cDNA Synthesis kit (Thermo Fisher Scientific, Inc.) according to the manufacturer's protocol. RT-qPCR analysis was performed using a PCR mixture containing $7.5 \mu \mathrm{M}$ of each primer and FastStart Universal SYBR Green Master (Rox) (Roche Diagnostics $\mathrm{GmbH})$. Amplifications were performed at $95^{\circ} \mathrm{C}$ for $15 \mathrm{sec}$ and at $60^{\circ} \mathrm{C}$ for $60 \mathrm{sec}$ for 40 cycles using a StepOnePlus Real-Time PCR system (Applied Biosystems; Thermo Fisher Scientific, Inc.). Each sample was examined in triplicate, and GAPDH was used as the internal control. The primer sequences are listed in Table I. The gene expression was quantified using the $2^{-\Delta \Delta \mathrm{Cq}}$ method (27).

Immunofluorescence assay. After cells were treated with vehicle or 17-AAG, cell samples were fixed with $4 \%$ paraformaldehyde for $15 \mathrm{~min}$ at room temperature and then permeabilized with $0.02 \%$ Triton X-100 for $5 \mathrm{~min}$. Subsequently, the cells were incubated with primary antibodies against Hsp90 (1:100; cat. no. ab13492; Abcam) or Sox 2 (1:100; cat. no. ab92494; Abcam) at $4^{\circ} \mathrm{C}$ overnight. On the following day, the samples were incubated with secondary antibody of Alexa Fluor ${ }^{\circledR}$ 594-conjugated AffiniPure Donkey Anti-Mouse IgG (H+L) (1:250; cat. no. 715-585-150; Jackson ImmunoResearch Laboratories, Inc.) and Alexa Fluor ${ }^{\circledR}$ 488-conjugated AffiniPure Goat Anti-Rabbit IgG $(\mathrm{H}+\mathrm{L})$ (1:250; cat. no. 111-545-144; Jackson ImmunoResearch Laboratories, Inc.) at room temperature for $1 \mathrm{~h}$. Finally, the nuclei were counterstained with DAPI at room temperature for $30 \mathrm{~min}$. Immunofluorescence was detected using a laser scanning confocal microscope (FV1000; Olympus Corporation).

Cell viability analysis. OS cells were plated at a density of $5 \times 10^{3}$ cells per well in a 96-well plate. After $24 \mathrm{~h}$, the cells were treated with $0.05,0.5,1,10$, or $50 \mu \mathrm{M} 17-\mathrm{AAG}$ for $72 \mathrm{~h}$. Inhibition of cell proliferation was analyzed using a Cell Counting Kit-8 (CCK-8; Dojindo Molecular Technologies, Inc.), according to the manufacturer's protocol. The plates 
Table I. Primers used for quantitative PCR analysis.

\begin{tabular}{|c|c|c|}
\hline Gene & Sequences $\left(5^{\prime}-3^{\prime}\right)$ & Product size (bp) \\
\hline \multirow[t]{2}{*}{ Sox 2} & F: ATGCACCGCTACGACGTGA & 198 \\
\hline & R: CCTGGAGTGGGAGGAAGAGGTA & \\
\hline \multirow[t]{2}{*}{ Oct-4 } & F: AGGATGTGGTCCGAGTGTGGTT & 191 \\
\hline & R: GTACAGTGCAGTGAAGTGAGGGCT & \\
\hline \multirow[t]{2}{*}{ Nanog } & F: GAGAAGAGTGTCGCAAAAAAGGA & 163 \\
\hline & R: TGAGGTTCAGGATGTTGGAGAGT & \\
\hline \multirow[t]{2}{*}{ Gli1 } & F: CCAAGCACCAGAATCGGACC & 140 \\
\hline & R: TTTGGTCACATGGGCGTCAG & \\
\hline \multirow[t]{2}{*}{ Hsp90 } & F: TTCACTGTGCGTGCTGACCAT & 289 \\
\hline & R: TGTCATCCTCCTCATCTGAACCC & \\
\hline \multirow[t]{2}{*}{ Ptch1 } & F: TGGAACGAGGACAAAGCGG & 202 \\
\hline & R: AGGCATAGGCGAGCATGAGTAA & \\
\hline \multirow[t]{2}{*}{ Smo } & F: TCCTGCGTCATCATCTTTGTCA & 267 \\
\hline & R: CGCACGGTATCGGTAGTTCTT & \\
\hline \multirow[t]{2}{*}{ GAPDH } & F: GGAAGCTTGTCATCAATGGAAATC & 168 \\
\hline & R: TGATGACCCTTTTGGCTCCC & \\
\hline
\end{tabular}

F, forward; R, reverse; Sox 2, sex determining region Y-box 2; Oct-4, octamer-binding transcription factor 4; Hsp, heat shock protein; Ptch1, protein patched homolog 1; Smo, smoothened, frizzled class receptor.

were incubated for an additional $2 \mathrm{~h}$, and the absorbance was then measured at $450 \mathrm{~nm}$. Experiments were performed in triplicate.

Cell transfection. The small interfering RNAs against the following genes were designed and synthesized by Guangzhou RiboBio Co., Ltd.: GSK3 $\beta$ sense, 5'-CUCAAGAACUGU CAAGUAATT-3' and antisense, 5'-UUACUUGACAGUUCU UGAGTT-3'. The siRNA was transfected into OS cells when they reached a confluence of $30-50 \%$ in 6 -well plates using Lipofectamine ${ }^{\circledR} 2000$ according to the manufacturer's protocol (Invitrogen; Thermo Fisher Scientific, Inc.) for $72 \mathrm{~h}$.

Western blot analysis. Cells were lysed in RIPA lysis buffer containing protease inhibitor and phosphatase inhibitor cocktails (Thermo Fisher Scientific, Inc.). Nuclear protein fractions were isolated using a Nuclear Protein Extraction kit according to the manufacturer's protocol (Thermo Fisher Scientific, Inc.). Equal amounts of protein (40 $\mu \mathrm{g}$ per lane) were resolved on $10 \%$ SDS-PAGE gels and transferred to PVDF membranes (EMD Millipore). The membranes were incubated with primary antibody overnight at $4^{\circ} \mathrm{C}$. The membranes were then washed with TBST (Tris-buffered saline with $0.05 \%$ Tween 20) and incubated with horseradish peroxidase-conjugated secondary antibodies. The primary antibodies used were Hsp90 (cat. no. ab13495), Ptch1 (cat. no. ab53715), Smo (cat. no. ab38686), Gli1 (cat. no. ab49314) (all from Abcam), $\beta$-actin (cat. no. 3700S), Akt (cat. no. 2920S), phosphorylated (p-) Akt (cat. no. 4060S), GSK-3 $\beta$ (cat. no. 9315S), and p-GSK-3 $\beta$ (cat. no. 9323S) (all from Cell Signaling Technology, Inc.) at a dilution of 1:1,000. Peroxidase-conjugated Affinipure goat anti-mouse (cat. no. 115-035-044; 1:5,000; Jackson ImmunoResearch Laboratories, Inc.) and anti-rabbit (cat. no. 111-035-003; 1:5,000; Jackson ImmunoResearch Laboratories, Inc.) secondary antibodies, were incubated with the membranes for $1 \mathrm{~h}$ at room temperature. Proteins were then visualized using SuperSignal ${ }^{\mathrm{TM}}$ West Femoto Maximum Sensitivity Substrate (Thermo Fisher Scientific, Inc.).

Statistical analysis. All numerical data are presented as the mean \pm standard deviation of three independent experiments, each performed in triplicate. SPSS (version 13.0; SPSS, Inc.) and GraphPad Prism version 5.0 (GraphPad Software, Inc.) were used for statistical analysis. Data were analyzed using a two-tailed Student's t-test or one-way analysis of variance followed by Tukey's post hoc test, unless otherwise specified. $\mathrm{P}<0.05$ was considered to indicate a statistically significant difference.

\section{Results}

OS sarcosphere cells exhibit notable stem cell-like properties and resistance to chemotherapy. Under serum-free conditions, CSCs form spheres that possess notable similarities to endogenous CSCs in human tumor tissues. Therefore, a sphere formation assay was performed to determine CSC self-renewal capacities. The self-renewal capacities of OS sarcosphere cells derived from the MG-63 and Saos- 2 cell lines were determined 1-2 weeks following disaggregation of sarcosphere cells with accutase and culture in SFM. The results demonstrated that sarcosphere cells derived from MG-63 and Saos-2 cells formed significantly more spherical colonies after 7 days of incubation in SFM, compared with the monolayer cells (Fig. 1A). To investigate the migratory and invasive abilities of sarcosphere and monolayer cells from the MG-63 and Saos-2 cell lines, the cells were cultured in Transwell chambers. After $24 \mathrm{~h}$ of 
A
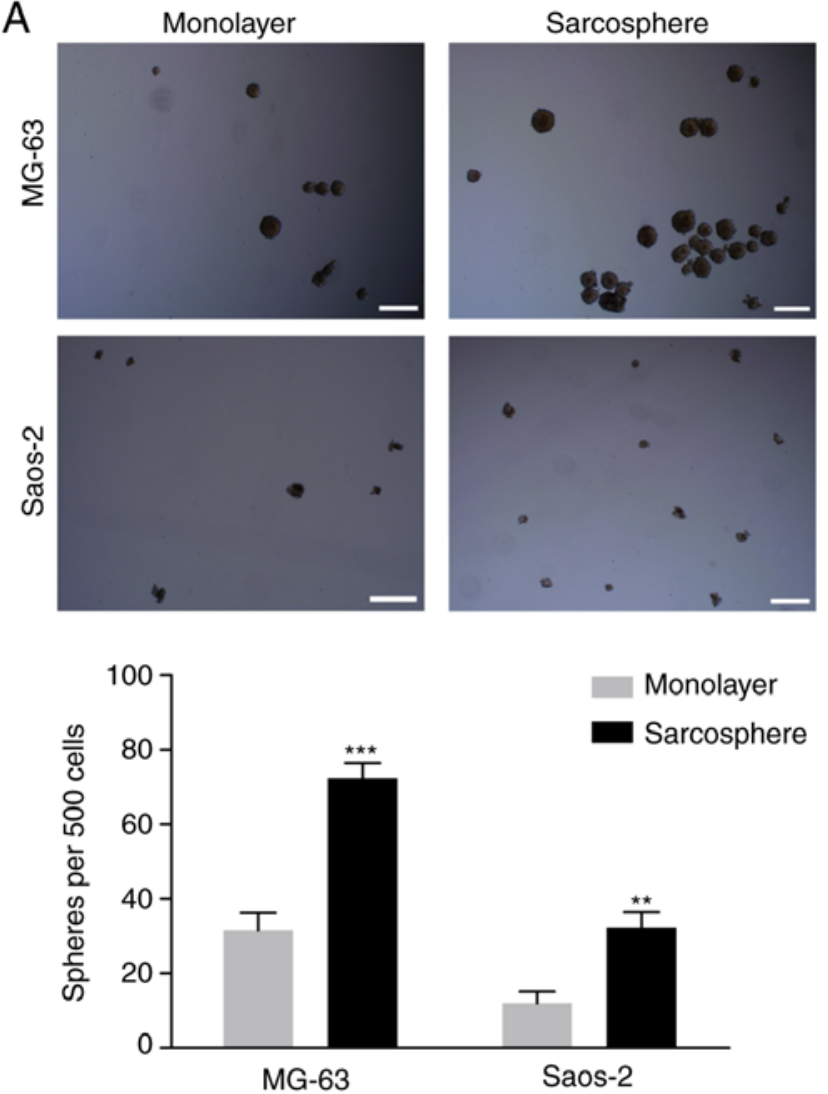

C
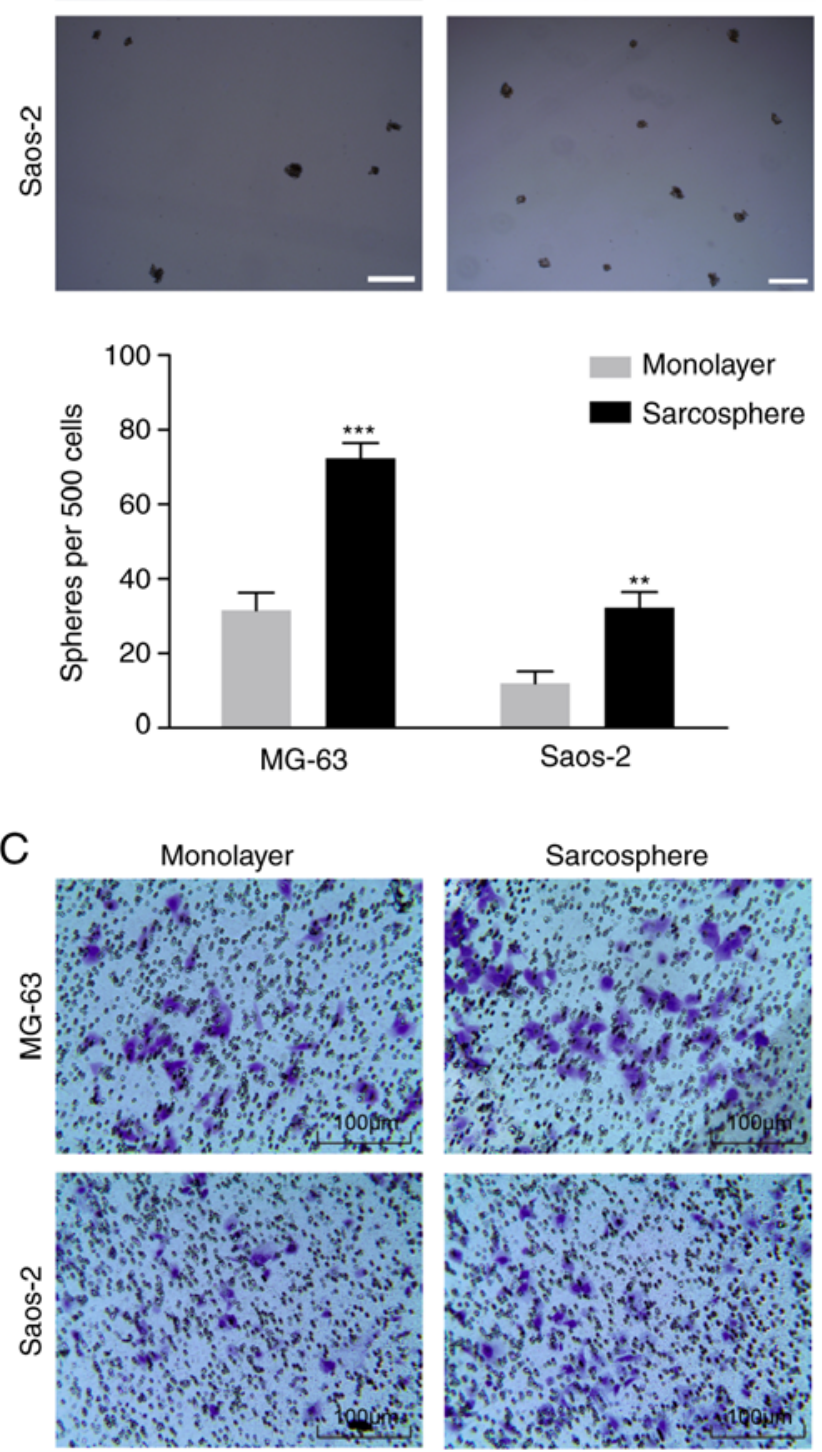

Saos-2
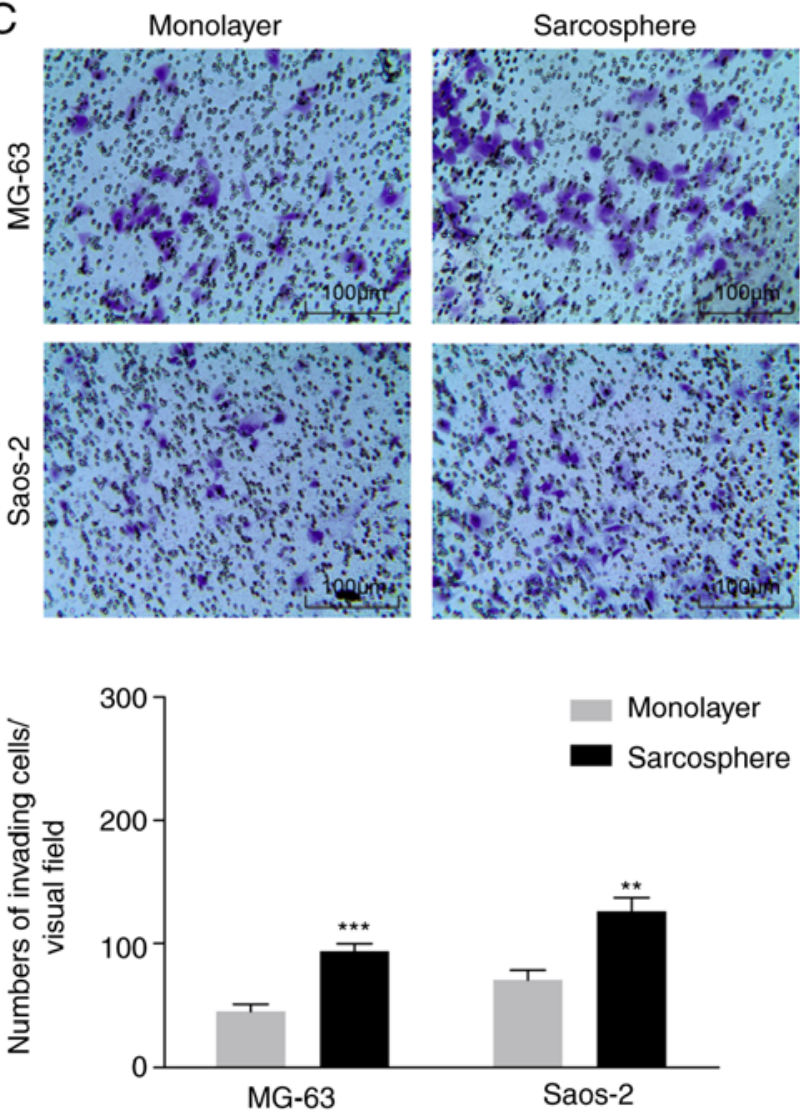

B
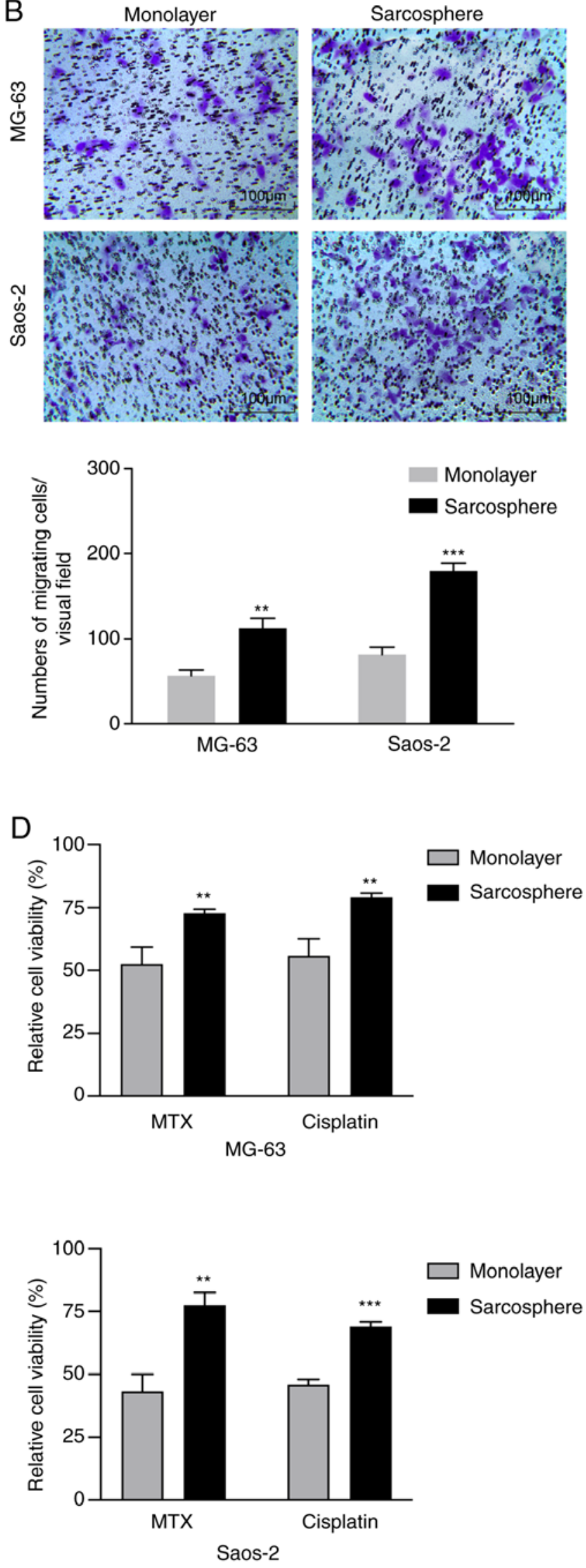

Figure 1. Osteosarcoma sarcosphere cells exhibit stem-like properties and chemotherapy resistance. (A) The spheroid-forming abilities of sarcosphere and monolayer cells derived from the MG-63 and Saos-2 cell lines were determined using low-attachment plates during methylcellulose culture Scale bar, $50 \mu \mathrm{m}$. (B) The migratory capacity of sarcosphere and monolayer cells derived from the MG-63 and Saos-2 cell lines was determined using a Transwell migration assay. (C) The invasive capacity of sarcosphere and monolayer cells derived from the MG-63 and Saos-2 cell lines was determined using a Matrigel invasion assay. (D) Treatment with methotrexate or cisplatin chemotherapy compared with DMSO. Data are presented as the mean \pm standard deviation of three independent experiments. ${ }^{* *} \mathrm{P}<0.01,{ }^{* * *} \mathrm{P}<0.001$. MTX, methotrexate. 
incubation, the number of sarcosphere cells from MG-63 and Saos-2 cells cultured on Transwell inserts was significantly higher compared with the number derived from monolayer cells (Fig. 1B). A Boyden chamber coated with Matrigel was used to determine changes in cell invasion ability after $24 \mathrm{~h}$ of incubation. Compared with the monolayer cells, the sarcosphere cells from the MG-63 and Saos-2 cell lines exhibited markedly increased invasion abilities (Fig. 1C).

Previous studies have demonstrated that CSCs are more resistant to chemotherapy compared with other OS cell populations $(28,29)$. Two commonly used chemotherapies for the treatment of OS, cisplatin and methotrexate, were used to examine the sensitivity of monolayer and sarcosphere cells derived from the MG-63 and Saos- 2 cell lines. The viability of monolayer cells was reduced by $45-57 \%$ when exposed to methotrexate at $50 \mathrm{nmol} / 1$, whereas methotrexate decreased the viability of sarcosphere cells by only $20-30 \%$. Monolayer cells from MG-63 and Saos-2 cells were also sensitive to cisplatin at $625 \mathrm{nmol} / 1$, with a reduction in cell viability of $40-55 \%$, whereas sarcosphere cells were relatively resistant to cisplatin, with cell viability decreasing by only $20-32 \%$ (Fig. 1D). These data indicated that OS sarcosphere cells possess CSC characteristics and are resistant to chemotherapy.

The expression of Hsp90 is positively associated with stem cell related-genes and CSC markers in OS sarcosphere cells. To determine the CSC characteristics of OS sarcosphere cells, RT-qPCR was employed to analyze the expression of Hsp90 and stem cell-related genes in MG-63- and Saos-2-derived monolayer and sarcosphere cells. The results demonstrated that sarcosphere cells from MG-63 and Saos-2 cells exhibited higher expression levels of Hsp90 and the stem cell markers Sox 2, Nanog and Oct-4 compared with the respective monolayer cells (Fig. 2A). Furthermore, immunofluorescence double-staining revealed that Hsp90 and Sox 2 were co-expressed in sarcosphere cells from the MG-63 and Saos-2 cell lineages (Fig. 2B).

To explore the association between Hsp90 and CSC markers in OSCs, the MG-63 and Saos-2 OS cell lines were cultured in SFM for 1-2 weeks, and flow cytometry analysis was performed to assess the expression of Hsp90 and CSC markers (CD133, ALDH1 and CD271). The results demonstrated that sarcosphere cells from the MG-63 and Saos-2 cell lines exhibited notably higher expression levels of Hsp90, CD133, ALDH1 and CD271 compared with monolayer cells (Fig. 2C).

Collectively, the data presented above suggest that Hsp90 expression is positively associated with the expression of stem cell-related genes and CSC markers in OS sarcosphere cells.

17-AAG suppress stem cell-like properties and chemoresistance in OS sarcosphere cells. To investigate whether 17-AAG could suppress stem cell-like properties in OS cells, a sphere formation assay was performed. 17-AAG treatment significantly reduced the number of spheres formed by sarcosphere cells from the MG-63 and Saos-2 cell lines (Fig. 3A). Furthermore, the effects of 17-AAG on the migration and invasion of sarcosphere cells derived from MG-63 and Saos-2 cells were assessed. 17-AAG reduced the migration of sarcosphere cells by $67.4-77.3 \%$ and the invasion of sarcosphere cells by $62.5-80.6 \%$ (Fig. 3B and C).
To determine whether 17-AAG suppressed chemoresistance in OS sarcosphere cells, the synergistic effects of 17-AAG with other commonly used chemotherapeutics were assessed. Compared with the reduction of viability by $22.8-31.4 \%$ with methotrexate chemotherapy alone, the viability of sarcosphere cells derived from MG-63 and Saos- 2 cells was reduced by $54.7-61.5 \%$ when treated with $50 \mathrm{nmol} / 1$ 17-AAG. Additionally, compared with the reduction of viability by $19.1-29.8 \%$ with cisplatin chemotherapy alone, the viability of sarcosphere cells from MG-63 and Saos-2 cells was reduced by 47.5-50.9\% when the cells were treated with 17-AAG (Fig. 3D).

These data suggest that 17-AAG suppressed CSC characteristics and chemotherapy resistance in OS sarcosphere cells.

17-AAG inhibits OSC characteristics and chemoresistance in OS sarcosphere cells through the downregulation of the Hedgehog signaling pathway. Inhibition of the Hedgehog signaling pathway can suppress CSC characteristics and reverse chemotherapy resistance. To elucidate the mechanisms underlying the anti-OSC effects induced by 17-AAG, RT-qPCR analysis and western blotting were used to assess the expression levels of the Hedgehog signaling pathway proteins Hsp90, Ptch1, Smo and Gli1, which were all notably higher in sarcosphere cells derived from MG-63 and Saos-2 cells compared with the respective monolayer cells (Fig. 4A). 17-AAG treatment of sarcosphere cells from MG-63 and Saos-2 cells significantly reduced the expression of Hsp90, Pcth1, Smo and Gli1 compared with the vehicle group (Fig. 4B). Taken together, these results demonstrated that 17-AAG inhibits OS stem cell-like properties and chemoresistance through the repression of the Hedgehog signaling pathway.

17-AAG suppresses Glil expression and activation mainly by blocking GSK3 $\beta$ activity. To gain insights into the molecular mechanism by which 17-AAG suppresses the Hedgehog pathway, we focused on Gli1, as it has been demonstrated that it plays a key role in GSK3 $\beta$-mediated tumor malignant behaviors (30). Therefore, it was hypothesized that GSK3 $\beta$ activity was involved in 17-AAG-induced Gli1 repression in OS sarcospheres. To verify this hypothesis, sarcosphere cells from the MG-63 and Saos-2 cell lines were treated with 17-AAG, and western blotting demonstrated that the expression of Gli1 and p-Akt was decreased, whereas the expression of p-GSK3 $\beta$ was increased (Fig. 5A). Furthermore, OS sarcosphere cells from MG-63 and Saos-2 cells were transfected with siRNAs targeting GSK $3 \beta$, and the results revealed that blocking GSK3 $\beta$ downregulated Gli1 expression (Fig. 5B). Thus, the inhibition of the Glil signaling pathway induced by 17-AAG primarily involved the repression of GSK $3 \beta$ activity.

\section{Discussion}

According to the OSC hypothesis, tumors of various origins are driven and maintained by a small fraction of OSCs (31). Recent studies have demonstrated that OSCs are associated with chemoresistance, relapse and metastasis of tumors $(32,33)$. Current chemotherapeutics for the treatment of OS primarily target proliferating tumor cells, which can significantly reduce tumor bulk, but exert minimal cytotoxic effects on OSCs. This results in tumor recurrence and lung metastasis, 
A

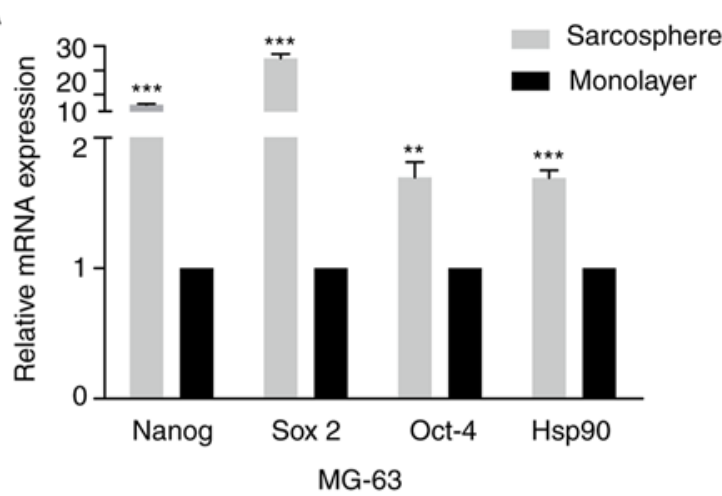

B
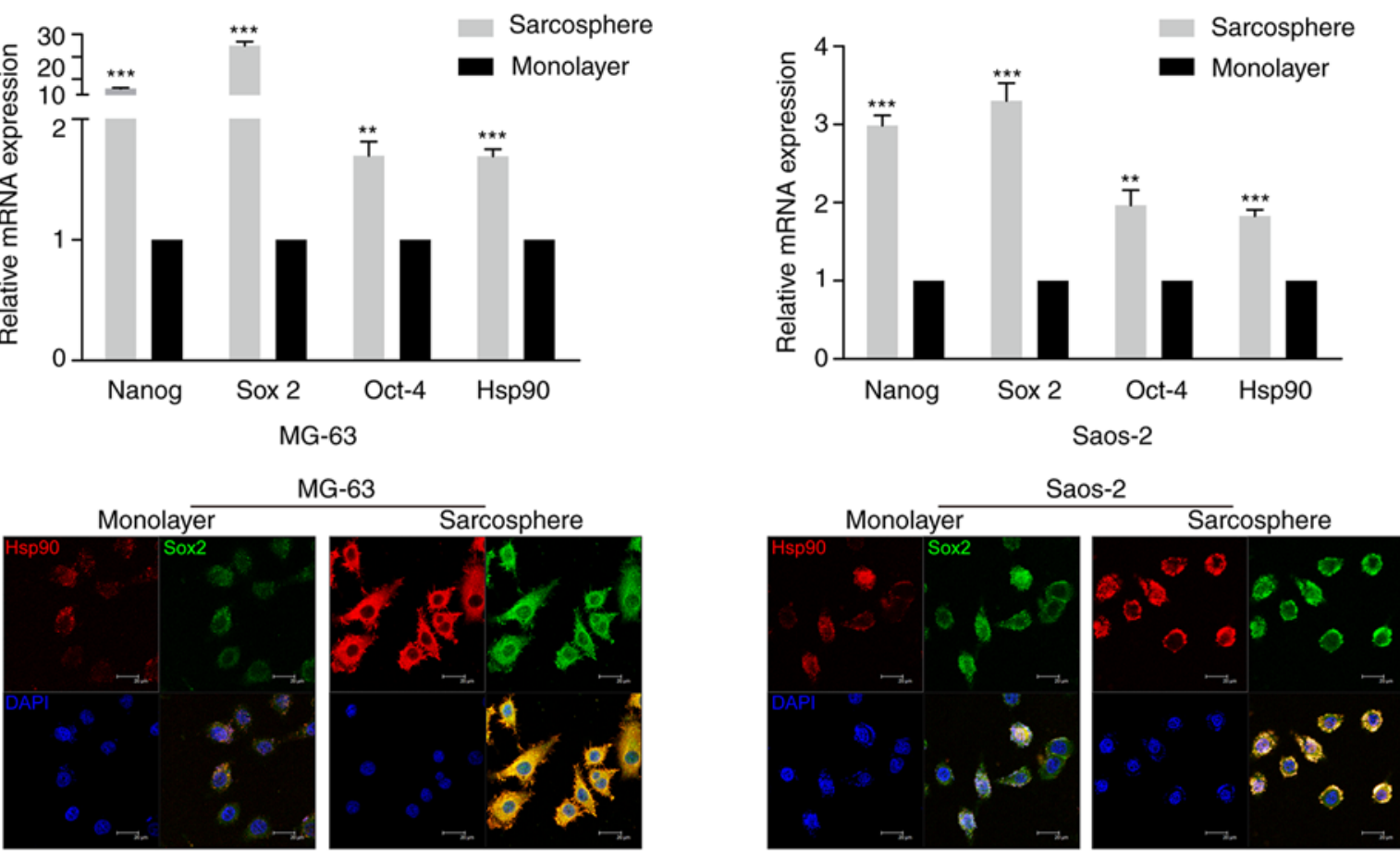

C

MG-63 Sarcosphere
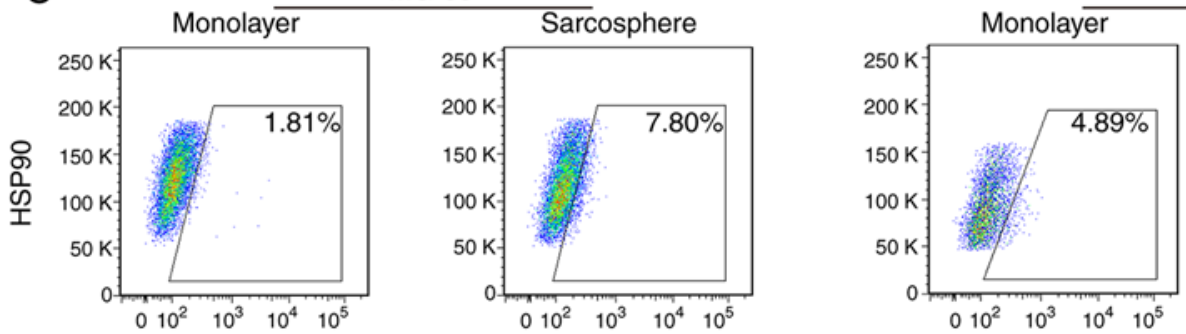

Saos-2
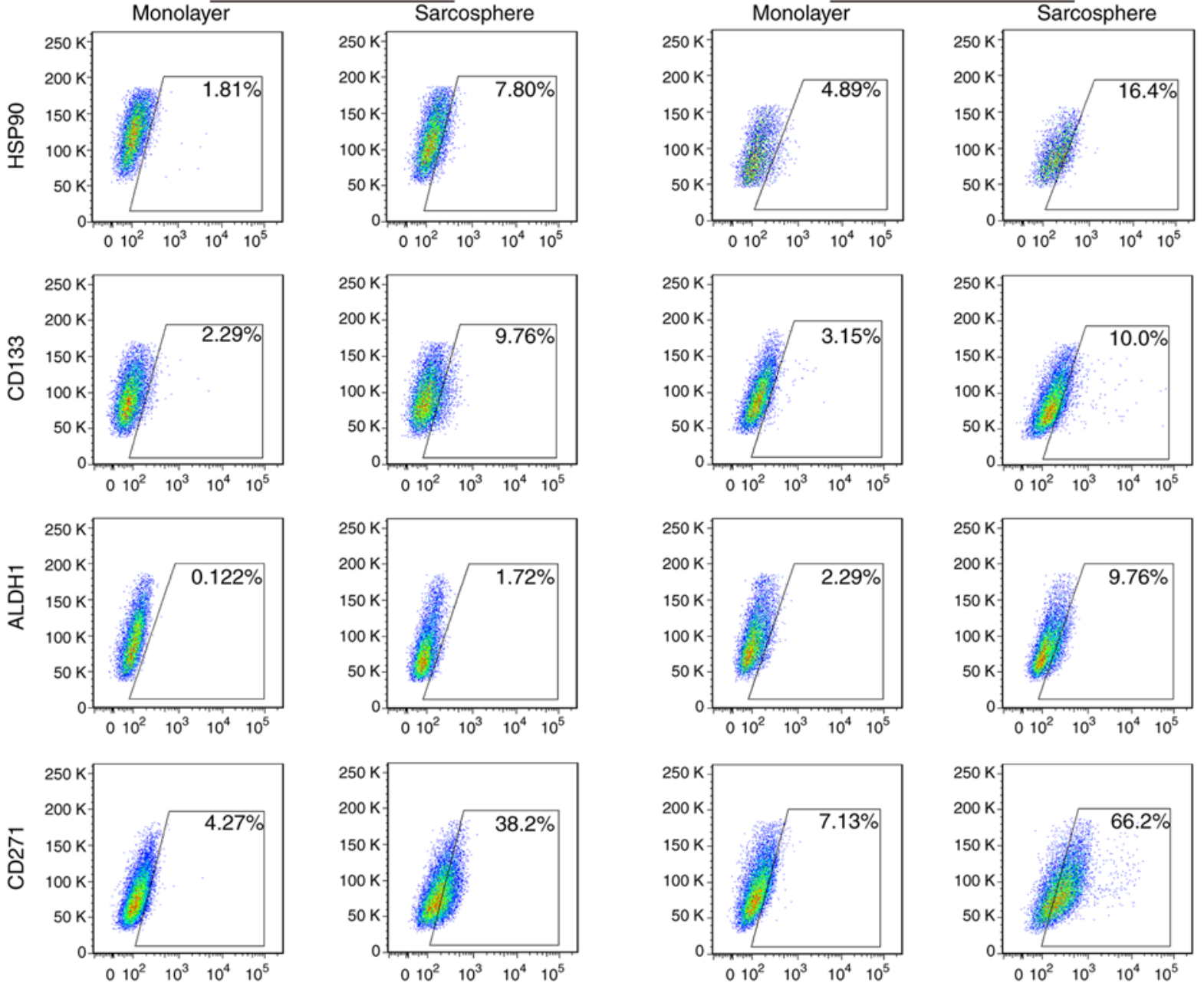

Figure 2. Hsp90 is positively associated with the expression of stem cell-related genes and CSC markers in osteosarcoma sarcosphere cells. (A) mRNA expression levels of Hsp90 and the stem cell markers Sox 2, Oct-4 and Nanog in sarcosphere and monolayer cells derived from MG-63 and Saos-2 cells. (B) Double staining for Hsp90 and Sox 2 using immunofluorescence in sarcosphere cells derived from MG-63 and Saos-2 cells. Scale bar, $50 \mu \mathrm{m}$. (C) Analysis of Hsp90, CD133, ALDH1 and CD271 expression in sarcosphere and monolayer cells derived from MG-63 and Saos-2 cells Hsp, heat shock protein; CSC, cancer stem cell; Sox 2, sex determining region Y-box 2; Oct-4, octamer-binding transcription factor 4; ALDH1, aldehyde dehydrogenase $1 .{ }^{* *} \mathrm{P}<0.01,{ }^{* * * *} \mathrm{P}<0.001$. 
A
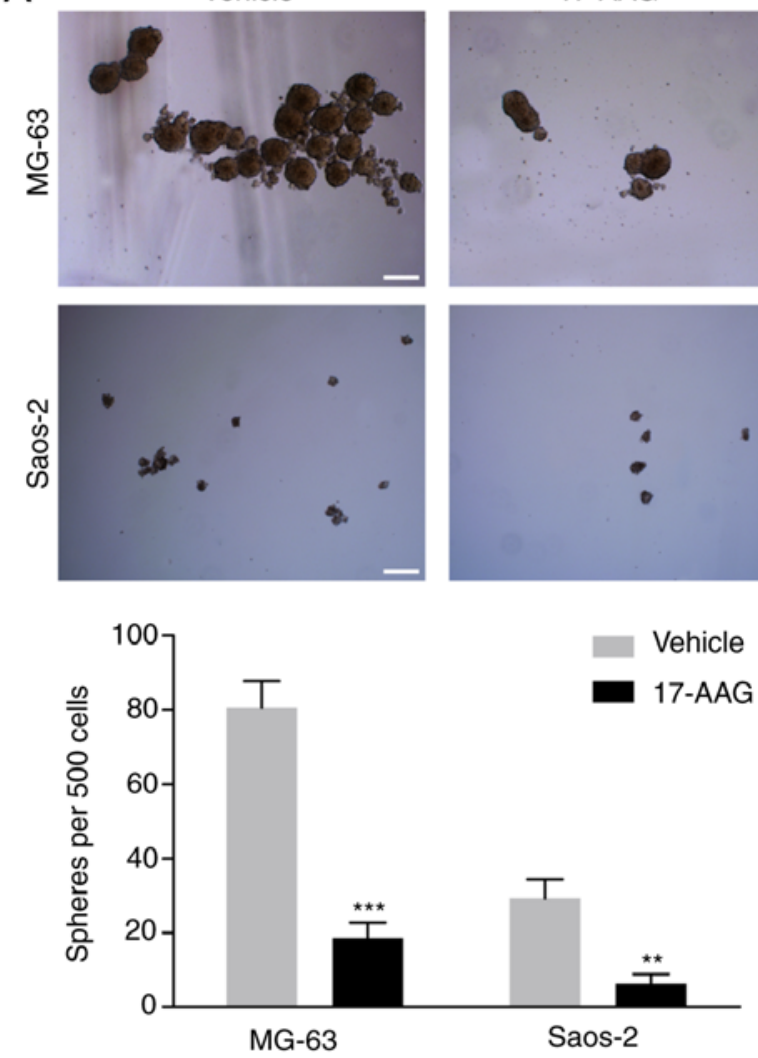

C
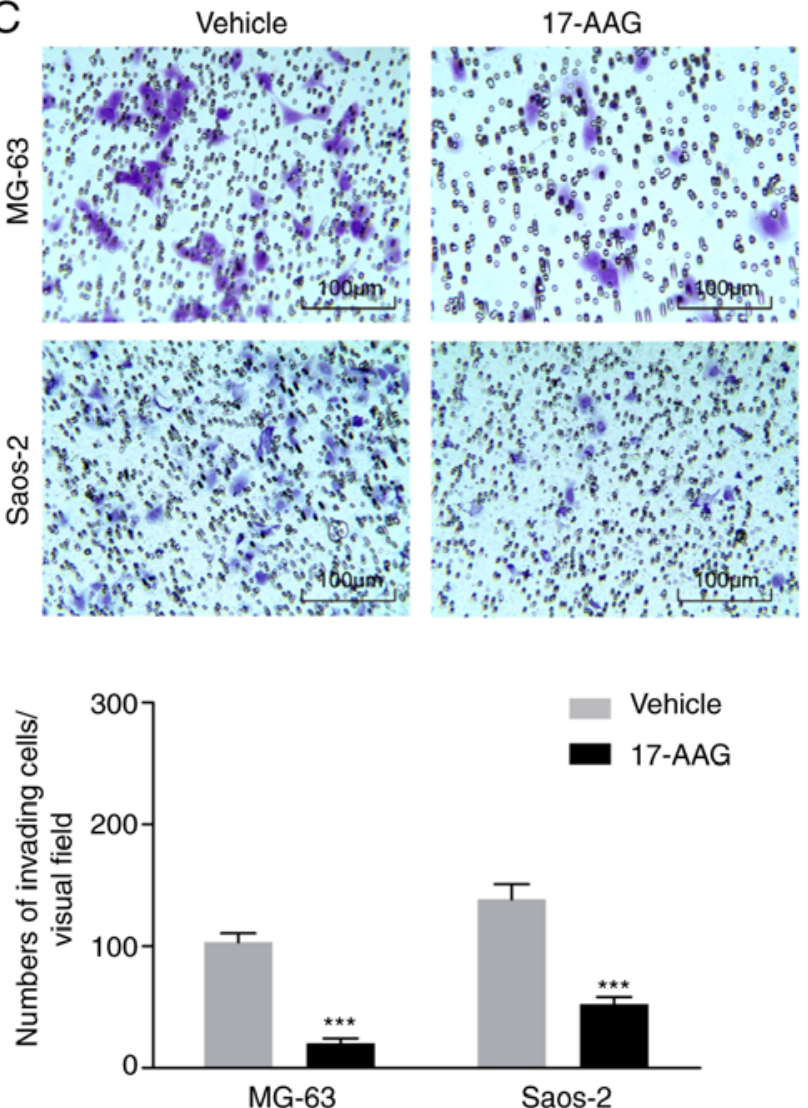

B
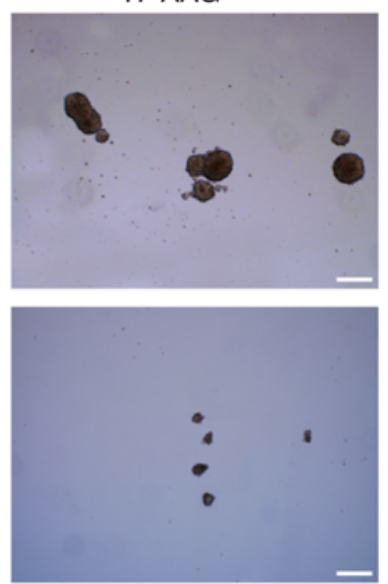

Saos-2

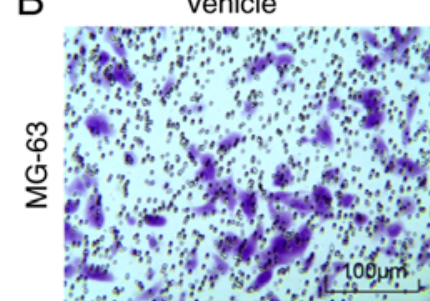

17-AAG
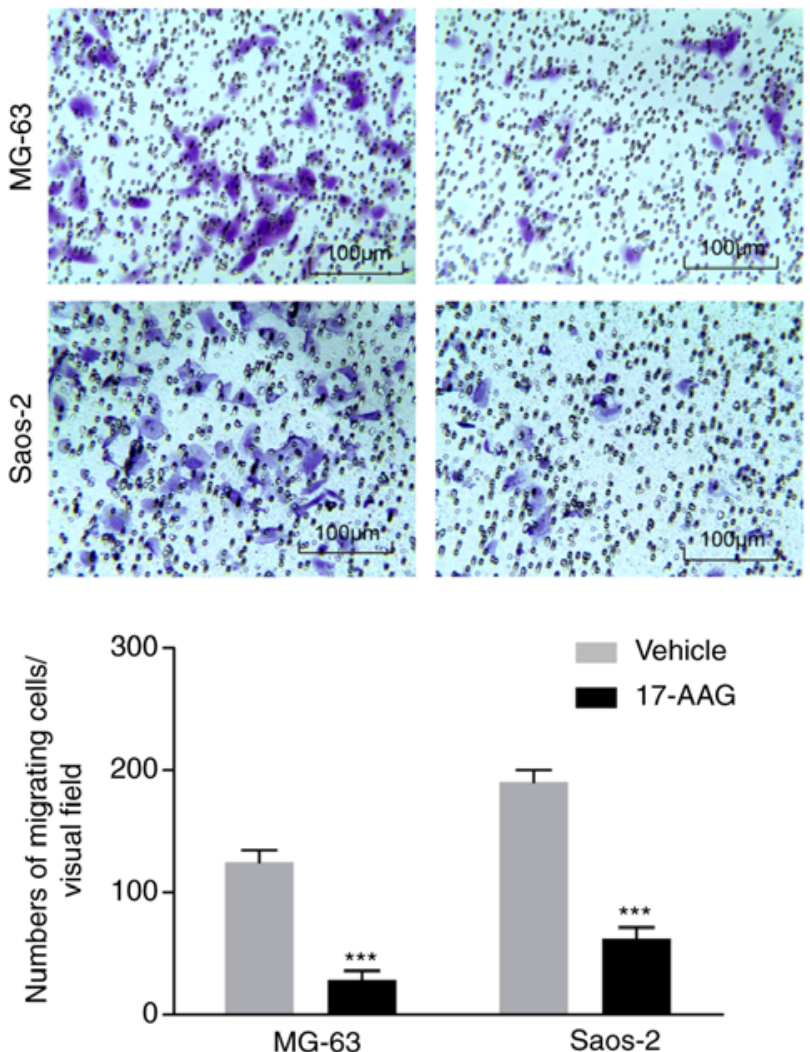

D
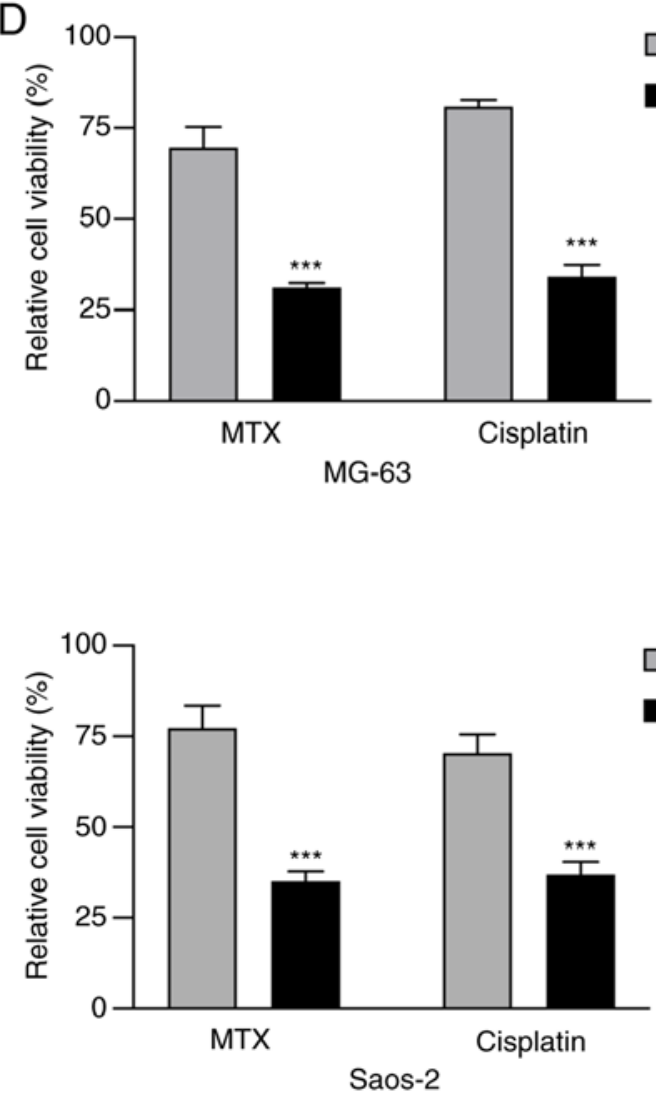

Figure 3. 17-AAG suppresses stem cell-like properties and chemoresistance of osteosarcoma sarcosphere cells. (A) The spheroid-forming abilities of sarcosphere cells derived from the MG-63 and Saos-2 cell lines were analyzed following treatment with $50 \mathrm{nM}$ 17-AAG using low-attachment plates during methylcellulose culture. Scale bar, $50 \mu \mathrm{m}$. (B) The migration capacity of sarcosphere cells derived from MG-63 and Saos-2 cells was determined in 17-AAG-treated cells using a Transwell migration assay. (C) The invasion capacity of sarcosphere cells derived from the MG-63 and Saos-2 cell lines following treatment with 17-AAG was determined using a Matrigel invasion assay. (D) Treatment with methotrexate or cisplatin chemotherapy compared with DMSO following treatment with 17-AAG. Data are presented as the mean \pm standard deviation of three independent experiments. ${ }^{* * *} \mathrm{P}<0.01,{ }^{* * * *} \mathrm{P}<0.001$. 

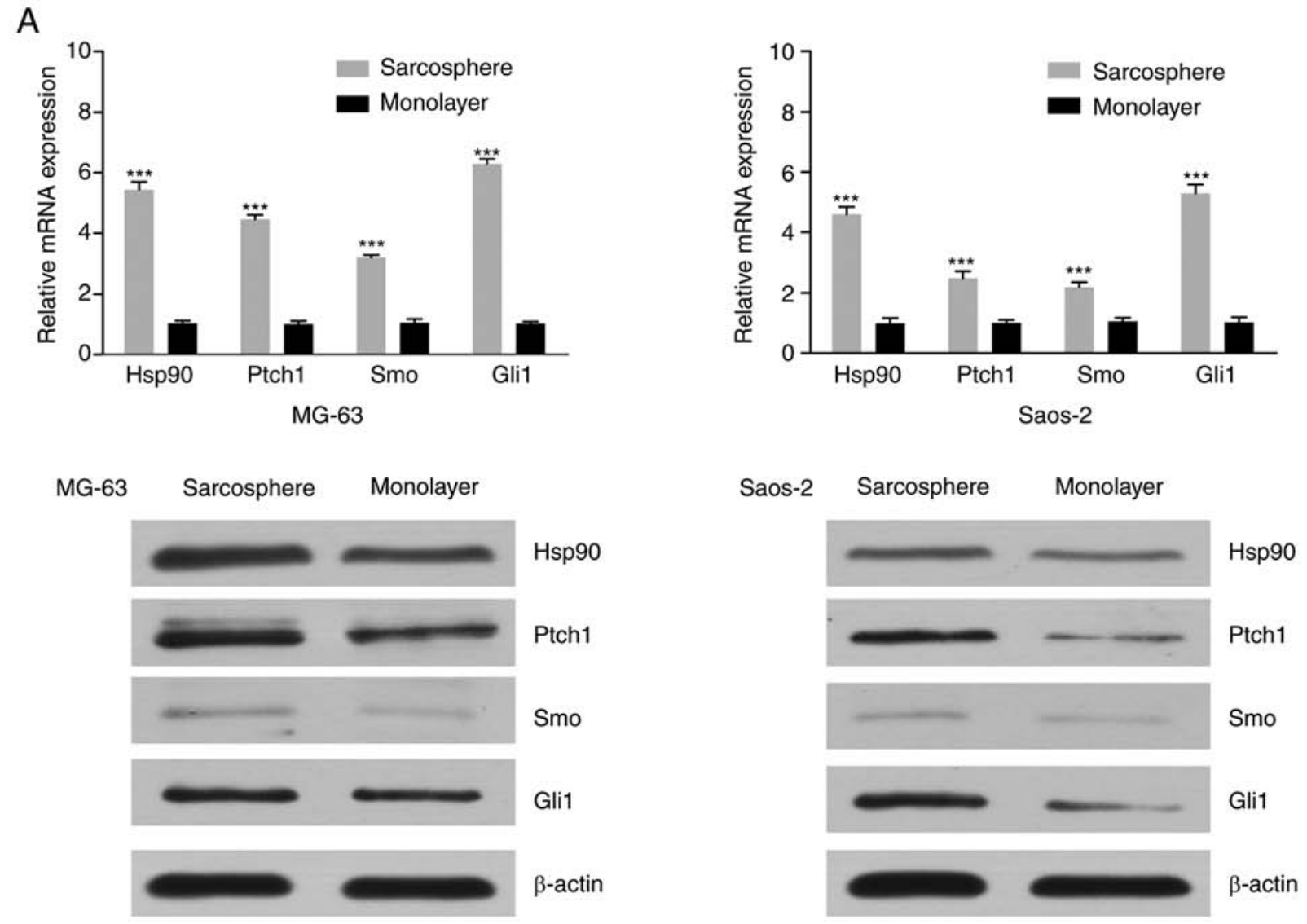

B
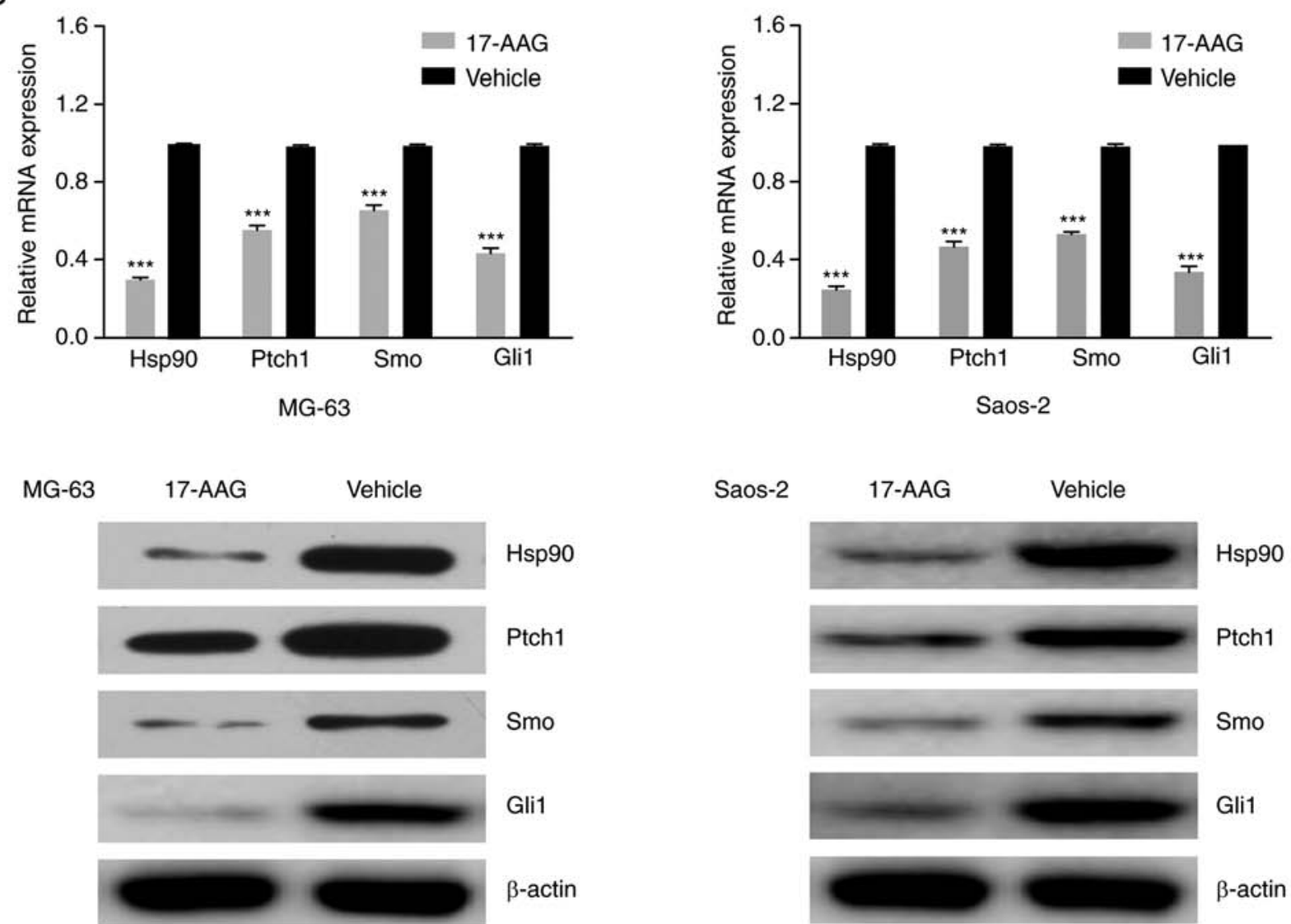

Figure 4. 17-AAG inhibits stem cell-like properties and chemoresistance of osteosarcoma sarcosphere cells through the repression of the Hedgehog/Gli1 pathway. (A) 17-AAG regulates the expression of Hedgehog/Gli1 pathway-associated genes and proteins in sarcosphere cells derived from the MG-63 and Saos-2 cell lines. (B) The expression of Hsp90 and Hedgehog/Gli1 pathway markers was measured using reverse transcription-quantitative polymerase chain reaction analysis and western blotting in sarcosphere cells derived from the MG-63 and Saos-2 cell lines. Data are presented as the mean \pm standard deviation. ${ }^{* * * *} \mathrm{P}<0.001$. Hsp, heat shock protein; Ptch1, protein patched homolog 1; Smo, smoothened, frizzled class receptor. 
A

MG-63

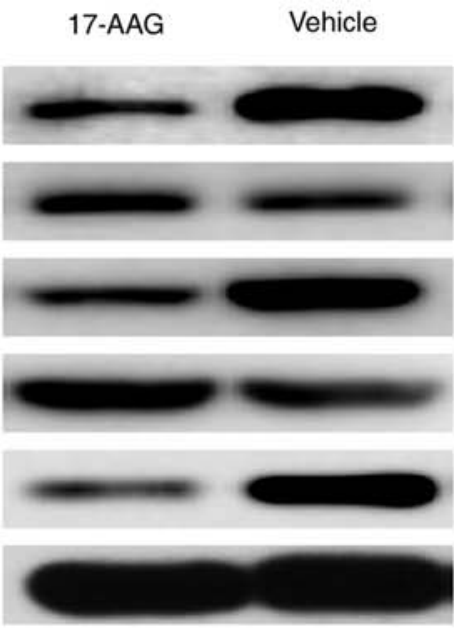

B

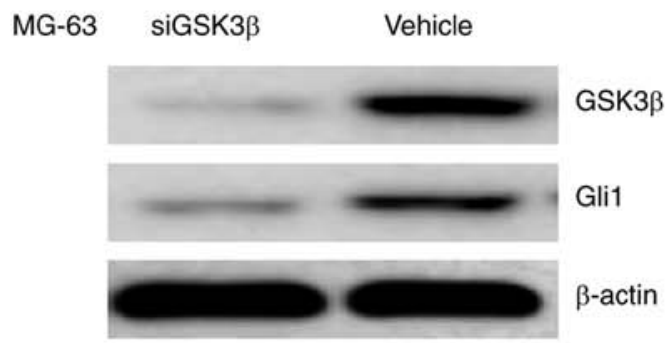

p-AKT

AKT

GSK3ß

Gli1

\section{Saos-2}

17-AAG

Vehicle

p-GSK3ß

$\beta$-actin

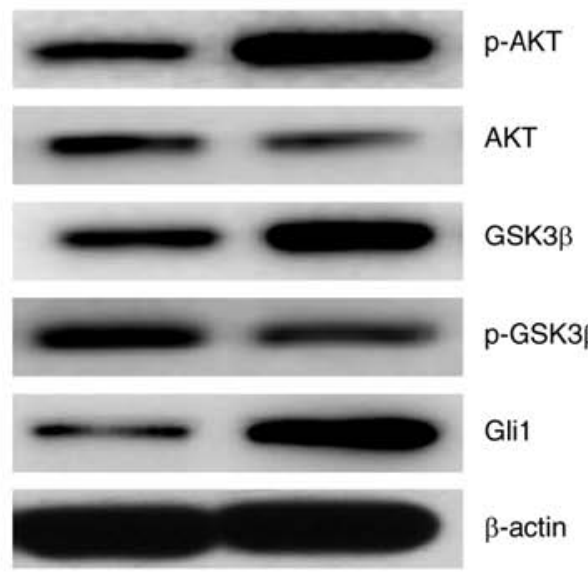

Saos-2

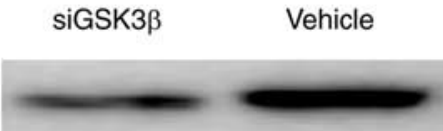

GSK3 $\beta$

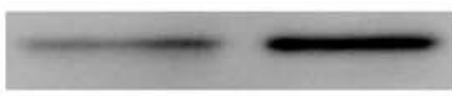

Gli1

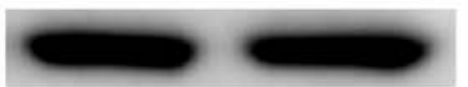

$\beta$-actin

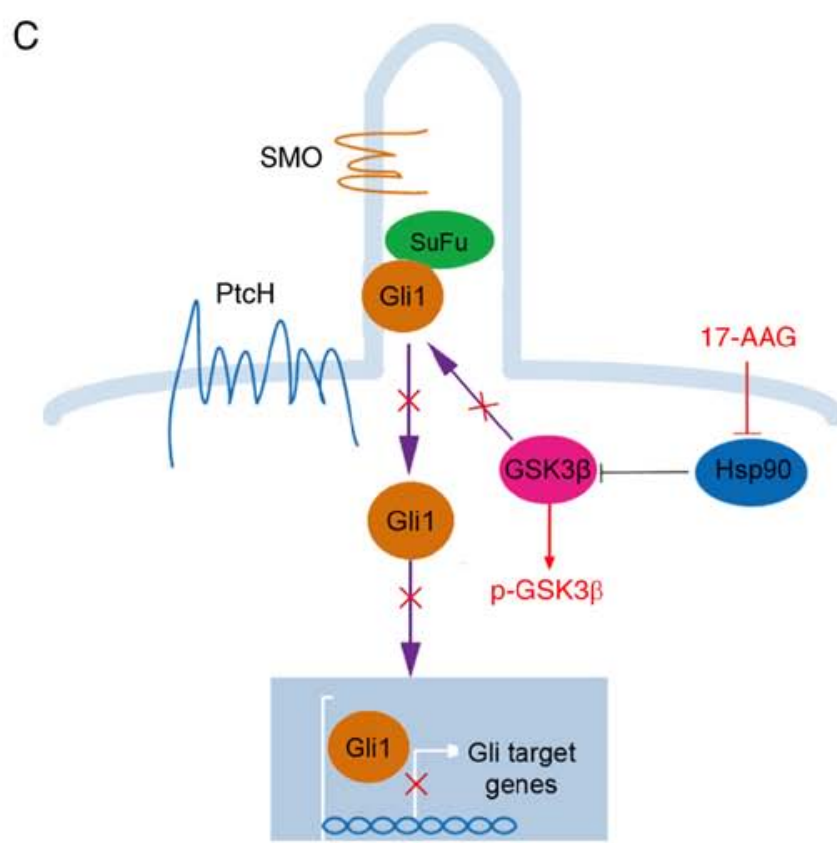

Figure 5. 17-AAG inhibits the Hedgehog/Gli1 pathway primarily by blocking GSK3 $\beta$ activity in osteosarcoma sarcosphere cells. (A) 17-AAG decreased the activity of GSK3 $\beta$, thereby affecting the expression of Gli1 in sarcosphere cells derived from the MG-63 and Saos-2 cell lines. (B) Western blotting was used to detect Gli1 protein expression in sarcosphere cells from MG-63 and Saos-2 cells transfected with si- GSK3 $\beta$. (C) Schematic diagram showing the hypothesized 17-AAG mediated regulation of the Hedgehog/Gli1 signaling pathway in osteosarcoma sarcosphere cells. 17-AAG inhibited the Hedgehog/Gli1 signaling pathway primarily by blocking GSK $3 \beta$ activity. siRNA, small interfering RNA; GSK, glycogen synthase kinase; Ptch1, protein patched homolog 1; Smo, smoothened, frizzled class receptor; Hsp, heat shock protein; SuFu, suppressor of fused homolog.

emphasizing the urgent need to develop new methods for directly targeting OSCs. Recent studies have reported that 17-AAG is a promising chemopreventive agent against CSCs in glioma and leukemia $(34,35)$. However, the research based on the chemotherapeutic activity of 17-AAG is in its early stages, and the underlying molecular mechanisms and genetic drivers controlling OSC phenotypes remain largely undefined at present. 
In the present study, a previously unrecognized role for 17-AAG as an Hsp90 inhibitor in the regulation of the OS cell stemness associated with drug resistance was identified. Furthermore, it was demonstrated that the Hedgehog signaling pathway was involved in 17-AAG-mediated OS cell stemness. First, a subpopulation of OSCs was isolated from the cell lines using a sphere formation culture assay, and these cells were shown to exhibit upregulated expression of a panel of stem cell-related genes and proteins compared with the respective monolayer cells, including CD133, ALDH1 and CD271, as well as Oct-4, Sox 2 and Nanog, all of which are known embryonic stem cell markers that are essential for the pluripotency and self-renewal of embryonic stem cells (36). The expression levels of Hsp90, Oct-4, Sox 2 and Nanog were increased in the sarcosphere cells, and these cells also exhibited increased self-renewal capacity, chemoresistance, and invasive and metastatic abilities, all of which were attenuated following Hsp90 inhibition using 17-AAG. OSCs were also eliminated through 17-AAG-mediated Hsp90 inhibition. Thus, it is possible that Hsp90 acts as an oncogene in OS, and the present study highlights its potential as a target for therapeutic intervention in OS.

Hsp90 is a molecular chaperone that plays a key role in the stabilization and function of several proteins that are dysregulated in various types of cancer, such as steroid receptors, transcription factors and kinases (37-39). By assessing the potential mechanisms of action of Hsp90 in regulating the stem-like properties and chemoresistance of sarcosphere cells, it was demonstrated that increased Hsp90 expression resulted in increased levels of Hedgehog signaling pathway-associated proteins. The Hedgehog signaling pathway is also considered to be crucially involved in the development and progression of several types of cancer, and its activity has been demonstrated to be increased and associated with cancer growth and drug resistance (40-43). Activated Gli proteins, primarily Gli1, translocate into the nucleus and stimulate the transcription of Hedgehog signaling pathway target genes, including Gli1, Smo and several other survival-promoting molecules (44-46). 17-AAG reduced the expression of Hsp90 and Gli1 in sarcosphere cells. These findings indicate that Glil is a significant prognostic marker and that 17-AAG inhibits stem cell-like properties and chemoresistance by inactivating the Hedgehog pathway.

Based on the results of the present study, it is suggested that 17-AAG exerts antitumor effects through its ability to modulate Glil expression and activation by blocking GSK3 $\beta$. However, further study is required to elucidate how 17-AAG inhibits GSK3 $\beta$ activity and represses the Hedgehog/Gli1 pathway. 17-AAG inhibited activation of GSK3 $\beta$ by increasing its phosphorylation level. Glil has been reported to be activated by several kinases, such as AKT, MAPK/ERK and mTOR/S6K1 $(39,47)$. In the present study, an association between GSK3 $\beta$ and Gli1 was demonstrated. As several kinases play a key role in the survival and growth of cancer cells, it has been reported that the activity of GSK $3 \beta$ may promote tumor growth in OS, and therapeutic targeting of GSK $3 \beta$ may be an effective approach to the treatment of OS (48). The Hedgehog signaling pathway is regulated by GSK-3 $\beta$, and the activity of this pathway is reduced when GSK-3 $\beta$ is suppressed (40). GSK-3 $\beta$ is a binding partner of suppressor of fused homolog $(\mathrm{SuFu})$. SuFu suppresses Gli activity by sequestering Gli in the cytoplasm (49-51). To further determine the potential anti-OSC molecular mechanism of action of 17-AAG, the effect of inhibiting Hsp90 on the stability and activity of mature GSK $3 \beta$ were assessed. The results revealed that 17-AAG inhibited the activation of GSK3 $\beta$ by increasing its phosphorylation level, and the expression of Gli1 was downregulated, suggesting an association between GSK3 $\beta$ and Gli1 (Fig. 5C). Thus, it may be inferred that $17-\mathrm{AAG}$ inhibited GSK $3 \beta$ through its ability to affect Gli1 expression and activation by blocking GSK3 $\beta$. However, how 17-AAG inhibits the activity of GSK3 $\beta$ and whether this inhibition is direct requires further investigation. Overall, 17-AAG has emerged as an effective strategy for targeting OSCs. To prolong drug circulation and reduce the toxicity of 17-AAG, improved delivery methods of 17-AAG, such as nanoparticles, liposomes, micelles and carbon nanomaterials, are required, and 17-AAG may prove to be of value as OS treatment in the future (52-54).

In summary, inhibition of OSC properties and chemoresistance by 17-AAG was found to be mediated through repression of the Hedgehog pathway, which suggests that 17-AAG may be a promising therapeutic agent for the treatment of OS. The present study not only identified the Smo/Glil axis as a critical regulator of OSC properties, but also demonstrated that GSK3 $\beta$ may be a novel therapeutic target as well as a significant prognostic marker for the clinical treatment of OS.

\section{Acknowledgements}

Not applicable.

\section{Funding}

The present study was funded by the National Natural Science Foundation of China (grant nos. 51973021 and 51932002), the Beijing Municipal Health Commission (grant nos. BMC2018-4 and BMC2019-9), the Natural Science Foundation of Beijing JiShuiTan Hospital (grant no. ZR-201906) and the CAMS Innovation Fund for Medical Sciences (grant no. 2017-I2M-3-005).

\section{Availability of data and materials}

All datasets generated and/or analyzed during the present study are included in this published article.

\section{Authors' contributions}

XS, YR, DFC designed the experiments; RZ and YSJ carried out the experiments; XS, RZ, YSJ, HQ, LC, RXW, CW and HQL were involved in data acquisition, analysis and interpretation; XS and YR drafted the manuscript and revised it critically for important intellectual content. All the authors have read and approved the final version of the manuscript.

\section{Ethics approval and consent to participate}

Not applicable.

\section{Patient consent for publication}

Not applicable. 


\section{Competing interests}

The authors declare that they have no competing interests.

\section{References}

1. Whelan JS and Davis LE: Osteosarcoma, chondrosarcoma, and chordoma. J Clin Oncol 36: 188-193, 2018.

2. Isakoff MS, Bielack SS, Meltzer P and Gorlick R: Osteosarcoma: Current treatment and a collaborative pathway to success. J Clin Oncol 33: 3029-3035, 2015.

3. Mirabello L, Troisi RJ and Savage SA: Osteosarcoma incidence and survival rates from 1973 to 2004: Data from the surveillance, epidemiology, and end results program. Cancer 115: 1531-1543, 2009.

4. Schiavone K, Garnier D, Heymann MF and Heymann D: The heterogeneity of osteosarcoma: The role played by cancer stem cells. Adv Exp Med Biol 1139: 187-200, 2019.

5. Brown HK, Tellez-Gabriel M and Heymann D: Cancer stem cells in osteosarcoma. Cancer Lett 386: 189-195, 2017.

6. Yan GN, Lv YF and Guo QN: Advances in osteosarcoma stem cell research and opportunities for novel therapeutic targets. Cancer Lett 370: 268-274, 2016.

7. Clevers H: The cancer stem cell: Premises, promises, and challenges. Nat Med 17: 313-319, 2011

8. Shackleton M, Quintana E, Fearon ER and Morrison SJ: Heterogeneity in cancer: Cancer stem cells versus clonal evolution. Cell 138: 822-829, 2009.

9. Fujiwara T, Katsuda T, Hagiwara K, Kosaka N, Yoshioka Y, Takahashi RU, Takeshita F, Kubota D, Kondo T, Ichikawa $\mathrm{H}$, et al: Clinical relevance and therapeutic significance of microRNA-133a expression profiles and functions in malignant osteosarcoma-initiating cells. Stem Cells 32: 959-973, 2014

10. Honoki K, Fujii H, Kubo A, Kido A, Mori T, Tanaka Y and Tsujiuchi T: Possible involvement of stem-like populations with elevated ALDH1 in sarcomas for chemotherapeutic drug resistance. Oncol Rep 24: 501-505, 2010.

11. Adhikari AS, Agarwal N, Wood BM, Porretta C, Ruiz B, Pochampally RR and Iwakuma T: CD117 and Stro-1 identify osteosarcoma tumor-initiating cells associated with metastasis and drug resistance. Cancer Res 70: 4602-4612, 2010

12. Tian J, Li X, Si M, Liu T and Li J: CD271+ osteosarcoma cells display stem-like properties. PLoS One 9: e98549, 2014.

13. Qi XT, Li YL, Zhang YQ, Xu T, Lu B, Fang L, Gao JQ, Yu LS, Zhu DF, Yang B, et al: KLF4 functions as an oncogene in promoting cancer stem cell-like characteristics in osteosarcoma cells. Acta Pharmacol Sin 40: 546-555, 2019.

14. Lee YH, Yang HW, Yang LC, Lu MY, Tsai LL, Yang SF Huang YF, Chou MY, Yu CC and Hu FW: DHFR and MDR1 upregulation is associated with chemoresistance in osteosarcoma stem-like cells. Oncol Lett 14: 171-179, 2017.

15. Dong J, Bi B, Zhang L and Gao K: GLIPR1 inhibits the proliferation and induces the differentiation of cancer-initiating cells by regulating miR-16 in osteosarcoma. Oncol Rep 36: 1585-1591, 2016

16. Qu H, Xue Y, Lian W, Wang C, He J, Fu Q, Zhong L, Lin N, Lai L, Ye Z and Wang Q: Melatonin inhibits osteosarcoma stem cells by suppressing SOX9-mediated signaling. Life Sci 207: 253-264, 2018

17. Maloney A and Workman P: HSP90 as a new therapeutic target for cancer therapy: The story unfolds. Expert Opin Biol Ther 2: $3-24,2002$

18. Neckers L: Hsp90 inhibitors as novel cancer chemotherapeutic agents. Trends Mol Med 8 (4 Suppl): S55-S61, 2002.

19. Barker CR, Hamlett J, Pennington SR, Burrows F, Lundgren K, Lough R, Watson AJ and Jenkins JR: The topoisomerase II-Hsp90 complex: A new chemotherapeutic target? Int J Cancer 118 2685-2693, 2006.

20. White PT, Subramanian C, Zhu Q, Zhang H, Zhao H, Gallagher R, Timmermann BN, Blagg BS and Cohen MS: Novel HSP90 inhibitors effectively target functions of thyroid cancer stem cell preventing migration and invasion. Surgery 159: 142-152, 2016.

21. Kim HB, Lee SH, Um JH, Kim MJ, Hyun SK, Gong EJ, Oh WK, Kang CD and Kim SH: Sensitization of chemo-resistant human chronic myeloid leukemia stem-like cells to Hsp90 inhibitor by SIRT1 inhibition. Int J Biol Sci 11: 923-934, 2015

22. Nanta R, Shrivastava A, Sharma J, Shankar S and Srivastava RK Inhibition of sonic hedgehog and PI3K/Akt/mTOR pathways cooperate in suppressing survival, self-renewal and tumorigenic potential of glioblastoma-initiating cells. Mol Cell Biochem 454: 11-23, 2019.
23. Kobune M, Takimoto R, Murase K, Iyama S, Sato T, Kikuchi S, Kawano Y, Miyanishi K, Sato Y, Niitsu Y and Kato J: Drug resistance is dramatically restored by hedgehog inhibitors in CD34+ leukemic cells. Cancer Sci 100: 948-955, 2009.

24. Yoon C, Park DJ, Schmidt B, Thomas NJ, Lee HJ, Kim TS, Janjigian YY, Cohen DJ and Yoon SS: CD44 expression denotes a subpopulation of gastric cancer cells in which Hedgehog signaling promotes chemotherapy resistance. Clin Cancer Res 20: 3974-3988, 2014.

25. Mastrangelo E and Milani M: Role and inhibition of GLI1 protein in cancer. Lung Cancer (Auckl) 9: 35-43, 2018.

26. Pan Y, Shu X, Sun L, Yu L, Sun L, Yang Z and Ran Y: miR-196a-5p modulates gastric cancer stem cell characteristics by targeting Smad4. Int J Oncol 50: 1965-1976, 2017.

27. Schmittgen TD, Zakrajsek BA, Mills AG, Gorn V, Siner MJ and Reed MW: Quantitative reverse transcription polymerase chain reaction to study mRNA decay: Comparison of end point and realtime methods. Anal Biochem 285: 194-204, 2000.

28. Martins-Neves SR, Paiva-Oliveira DI, Wijers-Koster PM, Abrunhosa AJ, Fontes-Ribeiro C, Bovee JV, Cleton-Jansen AM and Gomes CM: Chemotherapy induces stemness in osteosarcoma cells through activation of $\mathrm{Wnt} / \beta$-catenin signaling. Cancer Lett 370: 286-295, 2016.

29. Yu L, Fan Z, Fang S, Yang J, Gao T, Simoes BM, Eyre R, Guo W and Clarke RB: Cisplatin selects for stem-like cells in osteosarcoma by activating notch signaling. Oncotarget 7: 33055-33068, 2016.

30. Trnski D, Sabol M, Gojević A, Martinić M, Ozretić P, Musani V, Ramić S and Levanat S: GSK3 $\beta$ and Gli3 play a role in activation of Hedgehog-Gli pathway in human colon cancer-Targeting GSK $3 \beta$ downregulates the signaling pathway and reduces cell proliferation. Biochim Biophys Acta 1852: 2574-2584, 2015.

31. Izadpanah S, Shabani P, Aghebati-Maleki A, Baghbanzadeh A, Fotouhi A, Bisadi A, Aghebati-Maleki L and Baradaran B: Prospects for the involvement of cancer stem cells in the pathogenesis of osteosarcoma. J Cell Physiol 235: 4167-4182, 2020.

32. Liu B, Ma W, Jha RK and Gurung K: Cancer stem cells in osteosarcoma: Recent progress and perspective. Acta Oncol 50: 1142-1150, 2011.

33. Basu-Roy U, Basilico $\mathrm{C}$ and Mansukhani A: Perspectives on cancer stem cells in osteosarcoma. Cancer Lett 338: 158-167, 2013.

34. Sauvageot CM, Weatherbee JL, Kesari S, Winters SE, Barnes J, Dellagatta J, Ramakrishna NR, Stiles CD, Kung AL, Kieran MW and Wen PY: Efficacy of the HSP90 inhibitor 17-AAG in human glioma cell lines and tumorigenic glioma stem cells. Neuro Oncol 11: 109-121, 2009.

35. Newman B, Liu Y, Lee HF, Sun D and Wang Y: HSP90 inhibitor 17-AAG selectively eradicates lymphoma stem cells. Cancer Res 72: 4551-4561, 2012.

36. Amini S, Fathi F, Mobalegi J, Sofimajidpour H and Ghadimi T. The expressions of stem cell markers: Oct4, Nanog, Sox2, nucleostemin, Bmi, Zfx, Tcl1, Tbx3, Dppa4, and Esrrb in bladder, colon, and prostate cancer, and certain cancer cell lines. Anat Cell Biol 47: 1-11, 2014.

37. Sarto C, Binz PA and Mocarelli P: Heat shock proteins in human cancer. Electrophoresis 21: 1218-1226, 2000.

38. Staufer K and Stoeltzing O: Implication of heat shock protein 90 (HSP90) in tumor angiogenesis: A molecular target for anti-angiogenic therapy? Curr Cancer Drug Targets 10: 890-897, 2010.

39. Zuehlke A and Johnson JL: Hsp90 and co-chaperones twist the functions of diverse client proteins. Biopolymers 93: 211-217, 2010.

40. Zhao Z, Jia Q, Wu MS, Xie X, Wang Y, Song G, Zou CY, Tang Q, Lu J, Huang G, et al: Degalactotigonin, a natural compound from solanum nigrum L., inhibits growth and metastasis of osteosarcoma through GSK3 $\beta$ inactivation-mediated repression of the hedgehog/Gli1 pathway. Clin Cancer Res 24: 130-144, 2018

41. Stecca B, Mas C, Clement V, Zbinden M, Correa R, Piguet V, Beermann F and Ruiz I Altaba A: Melanomas require HEDGEHOG-GLI signaling regulated by interactions between GLI1 and the RAS-MEK/AKT pathways. Proc Natl Acad Sci USA 104: 5895-5900, 2007.

42. Wang Y, Ding Q, Yen CJ, Xia W, Izzo JG, Lang JY, Li CW, Hsu JL, Miller SA, Wang X, et al: The crosstalk of mTOR/S6K1 and Hedgehog pathways. Cancer Cell 21: 374-387, 2012.

43. Das S, Harris LG, Metge BJ, Liu S, Riker AI, Samant RS and Shevde LA: The hedgehog pathway transcription factor GLI1 promotes malignant behavior of cancer cells by up-regulating osteopontin. J Biol Chem 284: 22888-22897, 2009. 
44. Jiang $\mathrm{J}$ and Hui CC: Hedgehog signaling in development and cancer. Dev Cell 15: 801-812, 2008.

45. Ruiz I Altaba A: Gli proteins and Hedgehog signaling: Development and cancer. Trends Genet 15: 418-425, 1999.

46. Ng JM and Curran T: The Hedgehog's tale: Developing strategies for targeting cancer. Nat Rev Cancer 11: 493-501, 2011.

47. Katoh Y and Katoh M: Integrative genomic analyses on GLI1: Positive regulation of GLI1 by Hedgehog-GLI, TGFbeta-Smads, and RTK-PI3K-AKT signals, and negative regulation of GLI1 by Notch-CSL-HES/HEY, and GPCR-Gs-PKA signals. Int J Oncol 35: 187-192, 2009.

48. Tang QL, Xie XB, Wang J, Chen Q, Han AJ, Zou CY, Yin JQ, Liu DW, Liang Y, Zhao ZQ, et al: Glycogen synthase kinase-3 $\beta$, NF-KB signaling, and tumorigenesis of human osteosarcoma. J Nat Cancer Inst 104: 749-63, 2012

49. Hur EM and Zhou FQ: GSK3 signaling in neural development. Nat Rev Neurosci 11: 539-551, 2010.
50. Beurel E, Grieco SF and Jope RS: Glycogen synthase kinase-3 (GSK3): Regulation, actions, and diseases. Pharmacol Ther 148: 114-131, 2015.

51. Riobó NA, Lu K, Ai X, Haines GM and Emerson CP Jr: Phosphoinositide 3-kinase and Akt are essential for Sonic Hedgehog signaling. Proc Natl Acad Sci USA 103: 4505-4510, 2006.

52. Feng $X, X u$ W, Li Z, Song W, Ding $J$ and Chen $X$ : Immunomodulatory Nanosystems. Adv Sci (Weinh) 6: 1900101, 2019.

53. Yin F, Wang Z, Jiang Y, Zhang T, Wang Z, Hua Y, Song Z, Liu J, Xu W, Xu J, et al: Reduction-responsive polypeptide nanomedicines significantly inhibit progression of orthotopic osteosarcoma. Nanomedicine 23: 102085, 2020.

54. Ding J, Chen J, Gao L, Jiang Z, Zhang Y, Li M, Xiao Q, Lee SS and Chen X: Engineered nanomedicines with enhanced tumor penetration. Nano Today 29: 100800, 2019. 